\title{
Parental spanking of 1-year-old children and subsequent child protective services involvement ${ }^{\text {th }}$
}

\author{
Shawna J. Lee ${ }^{\mathrm{a}, *}$, Andrew Grogan-Kaylor ${ }^{\mathrm{a}}$, Lawrence M. Berger ${ }^{\mathrm{b}}$ \\ a University of Michigan, Ann Arbor, USA \\ ${ }^{\mathrm{b}}$ University of Wisconsin-Madison, USA
}

\section{A R T I C L E I N F O}

\section{Article history:}

Received 10 August 2013

Received in revised form 20 January 2014

Accepted 29 January 2014

Available online $\mathrm{xxx}$

\section{Keywords:}

Maltreatment

Abuse

Infant

Physical punishment

Discipline

Fragile families

Corporal punishment

\begin{abstract}
A B S T R A C T
The majority of U.S. parents spank their children, often beginning when their children are very young. We examined families $(N=2,788)$ who participated in a longitudinal community-based study of new births in urban areas. Prospective analyses examined whether spanking by the child's mother, father, or mother's current partner when the child was 1-year-old was associated with household CPS involvement between age 1 and age 5 . Results indicated that $30 \%$ of 1 -year-olds were spanked at least once in the past month. Spanking at age 1 was associated with increased odds of subsequent CPS involvement (adjusted odds ratio $=1.36,95 \% \mathrm{CI}[1.08,1.71], p<.01$ ). When compared to non-spanked children, there was a $33 \%$ greater probability of subsequent CPS involvement for children who were spanked at age 1 . Given the undesirable consequences of spanking children and a lack of empirical evidence to suggest positive effects of physical punishment, professionals who work with families should counsel parents not to spank infants and toddlers. For optimal benefits, efforts to educate parents regarding alternative forms of discipline should begin during the child's first year of life.
\end{abstract}

(C) 2014 Published by Elsevier Ltd.

Research continues to build a strong case that the use of physical punishment by parents is associated with higher levels of aggression, antisocial behavior, anxiety, and depression among children (Afifi, Mota, Dasiewicz, MacMillan, \& Sareen, 2012; Durrant \& Ensom, 2012; Gershoff, 2002; Gershoff et al., 2010; Grogan-Kaylor, 2004; Gershoff, Lansford, Sexton, DavisKean, \& Sameroff, 2012; Maguire-Jack, Gromoske, \& Berger, 2012; Taylor, Manganello, Lee, \& Rice, 2010). In part because of the adverse associations of spanking with children's developmental outcomes, professional organizations such as the American Academy of Pediatrics and the National Association of Social Workers have issued statements urging parents to avoid the use of physical discipline, and the American Academy of Pediatrics provides guidelines for effective discipline that include alternatives to spanking. Yet, as recently as 2010, 69\% of U.S. adults indicated that they supported the idea that "it is sometimes necessary to discipline a child with a good, hard, spanking" (Smith, Marsden, \& Hout, 2013).

Attitudes supporting the use of physical punishment are reflected in parental behavior. The majority of U.S. parents spank their children, often beginning when children are very young (Chung et al., 2009; Straus \& Stewart, 1999). Estimates from two large population-based studies indicated that over 5\% of mothers have spanked their 3-month-old children (Zolotor, Robinson, Runyan, Barr, \& Murphy, 2011), and approximately one-third of children age 2 or less have been spanked by a

\footnotetext{
The Fragile Families and Child Wellbeing Study is funded by NICHD grant numbers R01HD36916, R01HD39135, and R01HD40421, as well as a consortium of private foundations and other government agencies. The research study reported herein was supported by NICHD grant number K01HD054421 (to Berger) and the Vivian A. and James L. Curtis School of Social Work Research and Training Center (to Grogan-Kaylor).

* Corresponding author address: University of Michigan, School of Social Work, 1080 South University Avenue, Ann Arbor, MI 48109-1106, USA.
} 
caregiver (Maguire-Jack et al., 2012; Zolotor et al., 2011). Among 3-year-old children, 68\% have been spanked at least once, and 35\% have been spanked by their mother more than 2 times in the past month (Taylor, Manganello, et al., 2010). These numbers are even higher when accounting for spanking by fathers (Lee, Taylor, Altschul, \& Rice, 2013). Whereas the number of children ages 9 or older who have experienced physical discipline has declined substantially since 1975, there has been a much smaller decrease in the number of children ages 2-4 who have been spanked or slapped in the past year (Straus, 2011). The widespread prevalence of physical discipline of children age 3 and younger suggests that for most U.S. parents spanking young children remains within the purview of accepted practices.

One argument that is often invoked in support of spanking is that spanking is not thought to be abusive (Gagne, Tourigny, Joly, \& Pouliot-Lapointe, 2007; Taylor, Al-Hiyari, Lee, Priebe, \& Guerrero, 2014). That is, according to most states' definitions of child maltreatment, spanking even a very young child is not considered to be child abuse unless a physical mark (e.g., a bruise) is left on the child. However, few studies have examined whether spanking is associated with subsequent Child Protective Services (CPS) involvement or child maltreatment. Prior studies have looked at the predictors of spanking infants (e.g., Combs-Orme \& Cain, 2008; MacKenzie, Nicklas, Brooks-Gunn, \& Waldfogel, 2011; Zolotor et al., 2011) and have used cross-sectional data to show that spanking young children (Hemenway, Solnick, \& Carter, 1994; Trickett \& Kuczynski, 1986) or infants (Zolotor et al., 2011) was associated with concurrent use of physically abusive parenting behaviors (Hemenway et al., 1994; Trickett \& Kuczynski, 1986; Zolotor et al., 2011), higher levels of infant injury (Crandall, Chiu, \& Sheehan, 2006), and greater hormonal reactivity to stress among infants (Bugental, Martorell, \& Barraza, 2003). In addition, an evaluation by Chaffin et al. (2004) found that abusive parents who were already involved with the child welfare system and participated in a parenting program that explicitly counseled them not to use corporal punishment had lower levels of maltreatment recidivism (i.e., fewer CPS re-reports) than a control group of matched parents who received a similar intervention without content on spanking (Chaffin et al., 2004). These results imply that spanking is associated with CPS involvement, but do not indicate why this may be the case. Family coercion theory suggests that spanking that begins early in a child's life may be particularly problematic because coercive parenting behaviors often escalate over time in response to children's real or perceived misbehavior (Patterson, 1982). Such escalating behaviors may heighten the risk that abuse will occur. Indeed, parents report that instances of physical child abuse often start out as acts of "normal" child discipline (Durrant \& Ensom, 2012). Yet, we are aware of no prior longitudinal studies that employ a community-based sample to prospectively examine the link between parental spanking of infants and household risk of CPS involvement.

This study examined the hypothesis that parental spanking of 1-year-old children is related to a higher risk of subsequent household CPS involvement. Prospective logistic regression analyses of 2,788 mothers who participated in the Fragile Families and Child Wellbeing Study (FFCWS), a longitudinal, population-based study, were used to examine whether any instance of spanking in the prior month, when the index child was approximately 1-year of age, was associated with household CPS involvement at any point between the age 1 interview and the age 5 interview. Models controlled for potential confounds that have been linked to both higher levels of physical punishment and risk for CPS involvement, such as maternal race or ethnicity (Drake et al., 2011; MacKenzie et al., 2011) and maternal depression (Beauchaine, Webster Stratton, \& Reid, 2005; Chaffin et al., 2004; Dubowitz et al., 2011), as well as child sex, because boys are spanked more frequently than are girls (Gershoff, 2002).

\section{Method}

\section{Participants}

Data were drawn from FFCWS, a longitudinal birth cohort study of urban families comprised of a substantial (3:1) oversample of non-marital births relative to marital births. Children born to unmarried parents are more likely to experience poverty and parental relationship instability than are those born to married parents; the former have thus been designated 'fragile families' (Reichman, Teitler, Garfinkel, \& McLanahan, 2001). The original FFCWS cohort $(N=4,898)$ was recruited between 1998 and 2000 from a sample of new births within hospitals in 20 cities in the U.S. with populations of over 200,000. The Institutional Review Boards at Columbia University and Princeton University approved participant recruitment procedures. Verbal and written informed consent were obtained from participants at each interview. Reichman et al. (2001) provide a detailed description of the study design elsewhere.

FFCWS core interviews were conducted within a few days of the index children's birth and again when children were approximately age 1 (range: 9-36 months; $M=15$ months; $M d n=14$ months), 3 (range: $31-53$ months; $M=39$ months; $M d n=38$ months), 5 (range: 35-77 months; $M=64$ months; $M d n=64$ months), and 9 years (range: $104-143$ months; $M=112$ months; $M d n=110$ months). We used maternal self-report for all variables in this study, with data from the baseline, age 1 , and age 5 interviews. Data on spanking and family characteristics were from the baseline interview (at index children's birth) and when children were 1-year of age. Data on CPS involvement came from the In-Home Longitudinal Study of Pre-School Aged Children, a supplemental interview that collected additional information on child development when children were age 5. We excluded mothers that did not participate in the 1 -year core interview $(n=534)$ or the 5-year in-home supplement $(n=1,499)$. We then further eliminated cases in which CPS data were missing $(n=47)$ or the temporal ordering of spanking and CPS could not be determined $(n=10)$. A small amount of missing data $(<1 \%, n=20)$ on other study variables resulted in a final sample of 2,788 . 
Table 1

Maternal and household characteristics at age 1 or earlier, by household CPS involvement between age 1 and age $5(N=2,788)$.

\begin{tabular}{|c|c|c|c|c|}
\hline Variable & Total sample & No CPS involvement (90\%) & CPS involved (10\%) & $P$ \\
\hline Child was spanked in the past month, \% & 30 & 29 & 38 & $<.01$ \\
\hline Maternal major depression, \% & 16 & 15 & 28 & $<.001$ \\
\hline \multicolumn{5}{|l|}{ Mother's education, \% } \\
\hline$<$ High school & 33 & 32 & 42 & $<.001$ \\
\hline High school degree & 31 & 31 & 31 & \\
\hline Some college & 25 & 25 & 25 & \\
\hline College graduate & 11 & 12 & 3 & \\
\hline \multicolumn{5}{|l|}{ Mother's race/ethnicity, \% } \\
\hline White & 22 & 22 & 21 & .41 \\
\hline African American & 51 & 50 & 55 & \\
\hline Hispanic & 24 & 25 & 21 & \\
\hline Other & 3 & 3 & 3 & \\
\hline Child boy, \% & 52 & 52 & 52 & .87 \\
\hline Annual household income, $M(\mathrm{SD})$ (range: $0-400,000$ ) & $\$ 31,299(33,152)$ & $\$ 32,527(34,012)$ & $\$ 20,171(20,957)$ & $<.001$ \\
\hline Mother's age in years, $M(\mathrm{SD})$ (range: $15-47 \mathrm{y}$ ) & $25(6.0)$ & $25(6.1)$ & $24(5.6)$ & .06 \\
\hline
\end{tabular}

Abbreviations: $M$ indicates mean; SD indicates standard deviation; $\mathrm{y}=$ years.

Note: Rows and columns may not add to $100 \%$ due to rounding. Omnibus chi-square tests were conducted for binary and categorical variables (denoted as \%). Bonferonni corrected one-way analyses of variance (ANOVA) were conducted for continuous variables.

\section{Measures}

Key predictor variable: spanking at 1-year. Mothers were asked about their and their spouse/partners' spanking, with the following question: “Sometimes children behave pretty well and sometimes they don't. In the past month, have you spanked (child) because (he/she) was misbehaving or acting up?" Furthermore, if the child's father saw the child more than once in the past month, the mother was asked whether in the past month the child's father had spanked the child; and if the mother was living with or married to a new partner, the mother was asked whether in the past month her current partner had spanked the child. We created a dichotomous variable to indicate if, at the time of the age- 1 interview, children had been spanked in the past month, by their mother, father, and/or mother's current partner $(0=n o ; 1=y e s)$.

Outcome variable: household CPS involvement. The variable for CPS involvement was based on the question, "Since the child was born, has Child Protective Services contacted you about any child or children in this household?" $(0=n o, 1=y e s)$. Following precedent established by other researchers (Berger, Paxson, \& Waldfogel, 2009; Nam, Meezan, \& Danziger, 2006), these families were considered to be CPS involved (e.g., to have been investigated or assessed by CPS) because CPS is unlikely to contact a family regarding a "screened-out" child maltreatment report. For those who indicated having had CPS involvement, a subsequent question asked the month and year of the most recent CPS contact. We used this variable to ensure the temporal ordering of spanking and CPS involvement, i.e., that the most recent CPS contact occurred after the age 1 interview in which the data on spanking were obtained.

Covariates. The Composite International Diagnostic Interview-Short Form (CIDI-SF), Section A (Kessler, Andrews, Mroczek, Ustun, \& Wittchen, 1998) was used to measure major depression when the index child was age 1 , the same time that spanking was measured. The CIDI-SF uses the criteria set forth in the Diagnostic and Statistical Manual of Mental Disorders (DSM-IV) to determine the probability that the respondent would be diagnosed with major depression if given the full CIDI. Major depression was indicated by feelings of depression or anhedonia experienced for most of the day, every day, for at least 2 weeks. Participants were classified as likely to have major depression if they endorsed the screening items and 3 or more depressive symptoms (e.g., losing interest, feeling tired, change in weight) $(0=n o, 1=y e s)$. Other household and demographic covariates included maternal age at the time of the child's birth, race or ethnicity, education level, household income, whether the parents were married at the child's birth $(0=n o, 1=y e s)$, and child gender $(0=$ girl, $1=b o y)$. The household income variable represented the total amount of income received by all individuals in the mother's household in the preceding year.

\section{Statistical analysis plan}

Table 1 presents sample characteristics and bivariate analyses to assess between group differences by household CPS involvement status. Table 2 presents adjusted odds ratios (AOR) and 95\% confidence intervals (CI) for logistic regression analyses examining the association of spanking at age 1 and household CPS involvement between age 1 and age 5 (Model 1) and that same association adjusting for maternal and household characteristics (Model 2). All regression models accounted for two key aspects of the FFCWS sampling design: parental marital status at the time of the index child's birth and the city of the child's birth. Specifically, the models controlled for marital status at the time of the birth and the standard errors were adjusted for inter-cluster correlation among families residing in the same city at the time of the birth. Because odds ratios cannot be directly interpreted as statements about probabilities (Viera, 2008), we calculated the predicted probability of CPS involvement among "spanked" and non-spanked" children at age 1 (Long \& Freese, 2005). We then developed a real world example to translate the predicted probabilities into more easily understood natural frequencies applied to a hypothetical sample of families (Gigerenzer, 2011). 
Table 2

Logistic regression of maternal and household characteristics at age 1 or earlier predicting household CPS involvement between age 1 and age 5 ( $N=2,788)$.

\begin{tabular}{|c|c|c|c|c|}
\hline \multirow[t]{2}{*}{ Variable } & \multicolumn{2}{|c|}{ Model 1} & \multicolumn{2}{|c|}{ Model 2} \\
\hline & $\operatorname{AOR}(95 \% \mathrm{CI})$ & $p$ Value & AOR $(95 \% \mathrm{CI})$ & $p$ Value \\
\hline Child spanked in the past month ${ }^{a}$ & $1.43(1.16-1.76)$ & .001 & $1.36(1.08-1.71)$ & $<.01$ \\
\hline Maternal major depression ${ }^{\mathrm{a}}$ & & & $2.06(1.50-2.83)$ & $<.001$ \\
\hline Mother's education: <high school & & & 1 [Reference] & \\
\hline High school degree & & & $0.82(0.66-1.03)$ & .08 \\
\hline Some college & & & $0.89(0.62-1.28)$ & .53 \\
\hline College graduate & & & $0.35(0.14-0.87)$ & $<.05$ \\
\hline Mother's race/ethnicity: White & & & 1 [Reference] & \\
\hline African American & & & $0.66(0.43-1.01)$ & .06 \\
\hline Hispanic & & & $0.57(0.41-0.78)$ & $<.001$ \\
\hline Other & & & $0.90(0.49-1.66)$ & .74 \\
\hline Child boy $^{\mathrm{a}}$ & & & $0.95(0.71-1.27)$ & .75 \\
\hline Annual household income & & & $0.99(0.98-0.99)$ & $<.001$ \\
\hline Mother's age & & & $1.01(0.98-1.03)$ & .54 \\
\hline
\end{tabular}

Abbreviations: $\mathrm{AOR}=$ adjusted odds ratio; $\mathrm{CI}=$ confidence interval; $\mathrm{y}=$ years.

Note: All logistic regression models were adjusted for two important aspects of the FFCWS sampling design: city of the baseline core interview and parental marital status at birth.

a $0=$ no, $1=$ yes.

\section{Results}

As seen in Table 1, 30\% of 1-year-old children had been spanked at least once in the past month by their mother, father, or mother's current partner. Between the age 1 and the age 5 FFCWS interviews, $10 \%$ of families had experienced at least one visit from CPS. CPS involved families had higher rates of spanking. Among non-CPS involved families, 29\% of 1-year-olds had been spanked. Among CPS involved families, 38\% of 1-year-olds had been spanked. CPS involved families had higher levels of maternal depression, lower levels of household income, and lower levels of maternal educational attainment than non-CPS involved families.

As seen in Table 2, logistic regression results indicated that spanking was associated with a $36 \%$ greater likelihood of household CPS involvement, AOR = 1.36, 95\% CI [1.08, 1.71], $p<.01$ ), even after controlling for other important risk factors associated with spanking and CPS involvement, such as maternal depression, $\mathrm{AOR}=2.06,95 \% \mathrm{CI}[1.50,2.83], p<.001$ ).

The logistic regression model results provided an estimate of the association of each independent variable with CPS involvement. However, odds ratios cannot be directly interpreted as statements about probabilities (Viera, 2008). To gain a clearer picture of the relationship of our key independent variable of interest, parental spanking, with subsequent involvement in the child welfare system, we calculated predicted probabilities (see Fig. 1) of involvement with CPS between age 1 and age 5 at both levels of the corporal punishment variable (Long \& Freese, 2005). Results indicated that in absolute terms, there was 2.5 percentage point increase in involvement with CPS, from $7.6 \%$ to $10.1 \%$. This change in the probability of involvement with CPS can be interpreted in relative terms. When compared to children who were not spanked, this translates to a roughly 33\% increase in the probability of subsequent household CPS involvement for children in the FFCWS sample who were spanked at age 1 .

We use an idea inspired by the work of Gigerenzer (2011) to better understand predicted probabilities. For ease of comprehension, Gigerenzer (2011) suggested translating results about probabilities into frequencies applied to a hypothetical sample of people. Following this logic, we applied the results of our analysis to a hypothetical sample of 1,000 families. Our results indicated that $30 \%$ of 1 -year-olds were spanked in the week before the interview. Thus, in our hypothetical sample of 1,000 families, 300 1-year-old children would be in the "spanked" group. Of these 300, 30 (10.1\%) would live in households that experienced involvement with CPS when the child was between age 1 and age 5. Seven hundred (700) children (70\%) would be in the "not spanked" group, and of these 700 children, 53 (7.6\%) would live in households that experienced subsequent involvement with CPS. Thus, in our hypothetical sample of 1,000 families, a total of 83 households would have had subsequent involvement with CPS and, of those, 36\% (30/83) were "spanked" at age 1 . Children who were spanked at age 1 would be overrepresented among CPS-involved families relative to children who were not spanked; the former comprised $30 \%$ of the full hypothetical sample, but $36 \%$ of families involved with CPS.

What would happen if we were to intervene and eliminate use of spanking in these families? After removing the additional risk presented by spanking at age 1 , but holding other factors constant, it is plausible that the level of later CPS involvement among the "spanked" group would fall to that of the "not spanked" group. Thus, we can imagine that by eliminating spanking at age 1, the level of CPS involvement in the "spanked" group of 300 would decrease 2.5 percentage points (from $10.1 \%$ to $7.6 \%$ ), or $33 \%$, representing a net reduction in subsequent CPS involvement of approximately seven families per 1,000 . Our original calculation indicated that a total of 83 families would become involved with the child welfare system. By eliminating spanking at age 1, 76 children would be CPS involved, or 7.6\%. Thus, in our hypothetical sample of 1,000 families, the elimination of spanking translates to change of .7 percentage points (8.3-7.6\%), or an $8.4 \%$ reduction (0.7/8.3) in CPS involvement from the initial baseline over the 4 -year period from age 1 to age 5 . This finding assumes that our estimate 


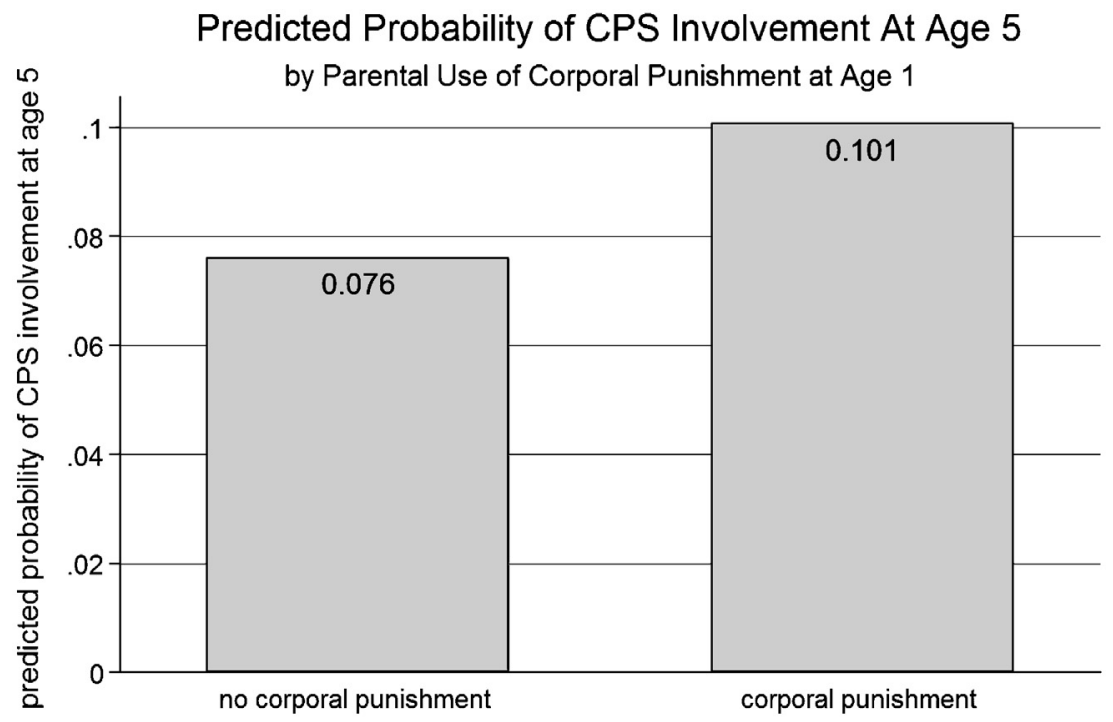

Fig. 1. Spanking at age 1 is associated with increased probability of subsequent CPS involvement.

represents the true causal effect of spanking on CPS involvement. To the extent that this estimate is upwardly biased (e.g., by omitted variables), we may be overestimating the decrease in CPS involvement that would result from eliminating spanking prior to age 1.

\section{Discussion}

There is growing consonance in the research literature demonstrating that physical punishment of children is associated with problematic outcomes such as child behavior problems and poorer mental and physical health (Afifi et al., 2012; Gershoff, 2002; Gershoff et al., 2010, 2012; Grogan-Kaylor, 2004; Maguire-Jack et al., 2012; Taylor, Manganello, et al., 2010). As such, many arguments in favor of spanking are increasingly being called into question by empirical evidence. Yet, behaviors of most parents in the United States do not reflect the current evidence, and spanking of young children is common (Taylor, Manganello, et al., 2010; Zolotor et al., 2011). Whereas both attitudes in support of physical punishment of older children and frequency of spanking older children have declined over the past several decades, there has been little change in either attitudes toward or frequency of spanking of infants and toddlers age 3 and younger (McCormick, 1992). Notably, we find that $30 \%$ of the 1-year-old children in this study's sample of urban families were spanked by at least one of their parental caregivers in the past month.

Although prior studies have shown that parental spanking has adverse consequences for child wellbeing, few studies have examined the consequences of spanking of 1-year-olds (for exceptions see studies by Bugental et al., 2003; Combs-Orme \& Cain, 2008; Crandall et al., 2006; Maguire-Jack et al., 2012; Zolotor et al., 2011). To our knowledge, this is the first study using prospective analysis of a community-based sample of families to show that, even after accounting for numerous household and parenting risk factors such as maternal depression, spanking of 1-year-old children is associated with increased risk for household CPS involvement.

When viewed in absolute terms, the elevation of risk found in this study might be construed as small. However, it should be noted that involvement with CPS, even among the families in our sample - who exhibit, on average, higher levels of social disadvantage than the general population - remains a relatively rare event experienced by about $10 \%$ of the families during the four year period currently under study. When events are rare, a small absolute change in the probability of an outcome may constitute a large relative change. A more accurate perspective on the relationship of parental spanking with later family CPS involvement may thus be obtained by contemplating the relative change in the probability of involvement with CPS. When compared to children who were not spanked by a parent at age 1, children who were spanked had $33 \%$ increase in the probability of household CPS involvement between age 1 and age 5. Assuming our regression estimates represent the causal effect of spanking on CPS involvement (a somewhat weighty assumption), eliminating spanking at age 1 could reduce CPS involvement by seven families in a hypothetical sample of 1,000 families; in other words, an $8.4 \%$ reduction in the number of children with CPS involvement over the four-year period between age 1 and age 5 .

This finding is particularly significant when viewed in light of the alarmingly high rates of child maltreatment in the United States. In 2012, 2.1 million maltreatment allegations were investigated by state CPS agencies, concerning the welfare of 3.2 million individual children; 686,000 children were found to be the victims of maltreatment (U.S. Department of Health and Human Services, 2012. Research shows that infants and toddlers experience the highest rates of maltreatment victimization (U.S. Department of Health and Human Services, 2012; Wu et al., 2004) and are most likely to experience serious injury 
or death due to maltreatment (U.S. Department of Health and Human Services, 2012). At a minimum, family involvement with CPS indicates that social welfare agencies have serious concerns about both family functioning and the safety of one or more children in the household, and CPS involvement represents a substantial increase in undesirable outcomes for young children, regardless of whether maltreatment claims of abuse are substantiated (Hussey et al., 2005; Kohl, Jonson-Reid, \& Drake, 2009). Intervention to reduce or eliminate spanking, particularly of young children, has the potential to contribute to the wellbeing of families and children who are at-risk of becoming involved with this system. Given that the child welfare system is notoriously overburdened and underfunded, when multiplied at the population level, an $8.4 \%$ reduction in the CPS caseload for families with young children could lead to real downstream benefits for the child welfare system as well as significant positive impact on other public health problems of concern, including physical and mental health problems.

The key finding of this study - that spanking at age one is associated with greater risk of household CPS involvement - is consistent with evidence from clinical samples (Beauchaine et al., 2005; Chaffin et al., 2004). For example, an intervention with physically abusive parents showed that reducing spanking and other coercive parenting behaviors was associated with lowered risk for recurrence of physical child abuse (Chaffin et al., 2004). Prior research also shows that children who are spanked are more likely to also be abused (Zolotor, Theodore, Chang, Berkoff, \& Runyan, 2008). Together, these findings suggest that spanking in general, and particularly the use of physical discipline with infants and toddlers, is a potential risk factor for maltreatment.

The results of this study can be viewed in the context of family coercion theory (Patterson, 1982). Prior studies show that there is high stability in the use of spanking over the course of early childhood, and that spanking contributes to more, rather than fewer, child behavioral problems (Gershoff, 2002; Lee, Altschul, \& Gershoff, 2013; Maguire-Jack et al., 2012). In other words, spanking has the iatrogenic effect of exacerbating the very behavioral problems, such as child aggression (e.g., hitting a sibling or playmate), that parents are often trying to extinguish, and parents appear to respond to greater child aggression by using spanking more (Lee, Altschul, \& Gershoff, 2013; Maguire-Jack et al., 2010). Spanking a 1-year-old as a form of discipline may be particularly misguided from the perspective of young children's cognitive abilities to understand and consistently respond to parental directives, and there is no empirical evidence to suggest that spanking at any age increases child compliance with parental directives (Gershoff, 2013). Given that the primary difference between spanking and physical abuse is one of severity (e.g., whether the child has a bruise or is otherwise injured), it is not surprising that discipline that starts out as spanking may, for some families, escalate to abuse.

In this paper, we focused on estimating the full association of spanking with CPS involvement. We did not attempt to explain or parse out potential mediators (mechanisms) through which spanking influences CPS involvement. Our approach makes the assumption that, if the presumed causal factor (spanking) is eliminated, then the mediators would not get 'enacted' and CPS involvement would decrease proportionate to its association with spanking. To the extent that spanking is not causally related to CPS involvement, or if we were interested in estimating the potential efficacy of compensatory interventions intended to reduce CPS involvement among children who are spanked, then it would be crucial to understand the mechanisms linking spanking and CPS involvement, and to estimate the proportion of the full association between spanking and CPS involvement that is related to specific mechanisms. Our analyses are silent in this regard.

\section{Implications}

One important way to stem the tide of child abuse is to address the parenting practices that increase the risk that maltreatment or abuse will occur. The results of this study suggest that spanking infants (1-year-olds) is one parenting practice worthy of preventive intervention efforts. There are numerous potential points at which practitioners who work with families can education parents about discipline. Perinatal well-baby clinical visits and home visitation following the birth of a child are important opportunities for pediatricians, nurses, and social workers to screen for parental use of physical discipline. Approximately $60 \%$ of pediatricians regularly screen parents for their use of aggressive discipline but, for the most part, they are more likely to provide parents with alternative strategies rather than to explicitly tell parents about the potential consequences associated with spanking young children (Scholer, Nix, \& Patterson, 2006). It is important to educate professionals who come into contact with new parents regarding research showing that spanking is harmful to children and to encourage communication of this information to parents.

There is promising evidence that parent education can be integrated into the systems of care that families routinely receive. One innovative approach is a multimedia DVD that presents information to parents about appropriate discipline and alternatives to spanking that parents view in pediatric waiting rooms (Scholer, Hudnut-Beumler, \& Dietrich, 2010; Scholer, Reich, Boshers, \& Bickman, 2011). In addition, a study showed that mothers who used baby books were less likely to spank (Reich, Penner, Duncan, \& Auger, 2012), suggesting that encouraging parents to document their child's developmental milestones may be another effective and non-intrusive way to reduce spanking of babies. Given the high rates of use of social media among new parents (Bartholomew, Schoppe-Sullivan, Glassman, Dush, \& Sullivan, 2012), FaceBook messages may provide another noninvasive outlet by which professionals can communicate with parents regarding age appropriate disciplinary strategies. Text4baby is a program that uses text messaging to communicate with mothers about caring for their new baby (Evans, Wallace, \& Snider, 2012; Jordan, Ray, Johnson, \& Evans, 2011; Whittaker et al., 2012), and the results of this study suggest that mothers may benefit from educational messages regarding not spanking or hitting babies. Even among parents who are at high risk for (e.g., Chaffin et al., 2004), education to avoid use of spanking is an important step that may reduce the likelihood of future abuse. 


\section{Study limitations}

A potential limitation of this study is that, similar to some prior research that also used large representative samples of families (e.g., Berger et al., 2009; Nam et al., 2006; Zolotor et al., 2008), CPS involvement is based on maternal selfreport rather than administrative (or at least independent) data. Administrative or independent report of CPS involvement is not available in the FFCWS. Use of self-report to measure CPS involvement may introduce underreporting due to selfpresentational biases, which would bias our estimates toward zero, making them conservative or lower-bound estimates of the actual association between spanking at age 1 and CPS involvement. It is also possible that respondents underreported both spanking and CPS involvement, which would also bias the association between these variables toward zero. As a result we may be underestimating the effect of early spanking on later CPS involvement, and caution must be exercised in generalizing the study findings. As is the case with any study, it is important in future research to replicate the findings, ideally, using CPS administrative data.

The validity of maternal reported CPS used in the FFCWS study has been examined in prior studies showing that the CPS involvement rate in FFCWS is comparable to rates found among similarly disadvantaged populations, including administrative data in the Illinois Families Study (McDaniel \& Slack, 2005; Slack et al., 2011) and nurse practitioners reports in the Infant Health and Development Study (Berger \& Brooks-Gunn, 2005). For example, in one study that compared maltreatment rates across several different studies, $7 \%$ of the FFCWS sample indicated that they were investigated by CPS. By comparison, $9 \%$ of current and former welfare recipients in the Illinois Families Study, a less advantaged population than our sample, had a CPS investigation (Slack et al., 2011). We also compared our figures to administrative data from Wisconsin and found that $4 \%$ of all families involved with one or more social welfare benefits programs and $12 \%$ of families who had received TANF (cash welfare) between 2006 and 2011 had been investigated by CPS. These comparisons suggest that the rate of CPS involvement using a self-reported CPS measure in FFCWS are what would be expected given the sample's characteristics.

This limitation must be viewed in light of study strengths. We isolate the timing of our key variables allowing for prospective analysis of the link between spanking and CPS involvement. Furthermore, the majority of prior studies of spanking examine spanking by mothers only. Failure to include fathers or father figures is problematic because those studies that have examined mothers and fathers jointly show that, even though fathers spend less time caring for young children than do mothers, fathers have high rates of physical punishment of young children that are nearly comparable to mothers (Lee, Altschul, et al., 2013; Lee, Taylor, et al., 2013; Straus \& Stewart, 1999; Taylor, Lee, Guterman, \& Rice, 2010). By including spanking by mothers, fathers, and/or mothers' current partners, we provide a more accurate estimate of the incidence of spanking of 1-year-old children and therefore have more confidence in study estimates that link spanking by any parental caregiver in the child's household to subsequent household risk for CPS involvement.

\section{Conclusions}

Implications of this study extend to efforts to promote the wellbeing of children and prevent child maltreatment. Prior research indicates that spanking increases adverse developmental outcomes such as child aggressive behavior. Findings from the current study indicate that spanking young children may also increase the likelihood that a family will face a CPS investigation. As a result, mothers and fathers of infants and toddlers are in need of information about age appropriate expectations of child behavior, as well as information about appropriate use of discipline, beginning in hospitals at the child's birth and at well-baby visits during the first year. Educational efforts, such as the Connected Kids initiative (American Academy of Pediatrics, 2010), should continue to promote non-aggressive child discipline techniques and reinforce the negative consequences of spanking. To prevent maltreatment and more generally nonproductive or harmful parenting behaviors, parenting programs targeting parents at-risk or already involved with CPS should take an assertive stance against spanking, regardless of the child's age. Professional organizations that are concerned with the prevention of child abuse and neglect, such as the International Society for the Prevention of Child Abuse and Neglect, should follow the lead of the American Academy of Pediatrics and National Association of Social Workers as well as other leading professional organizations, and urge parents to avoid use of spanking, given the negative consequences of using spanking and no empirical evidence to suggest any positive or neutral effects of physical discipline.

\section{Conflicts of interest}

The authors report no potential conflicts of interest, including relevant financial interests, activities, relationships, and affiliations.

\section{References}

Afifi, T. O., Mota, N. P., Dasiewicz, P., MacMillan, H. L., \& Sareen, J. (2012). Physical punishment and mental disorders: Results from a nationally representative U.S. sample. Pediatrics, 130, 184-192.

Bartholomew, M. K., Schoppe-Sullivan, S. J., Glassman, M., Dush, C. M., \& Sullivan, J. (2012). New parents' Facebook use at the transition to parenthood. Family Relations, 61, 455-469.

Beauchaine, T. P., Webster Stratton, C., \& Reid, M. J. (2005). Mediators, moderators, and predictors of 1-year outcomes among children treated for early-onset conduct problems: A latent growth curve analysis. Journal of Consulting and Clinical Psychology, 73, 371-388. 
S.J. Lee et al. / Child Abuse E' Neglect $x x x(2014) x x x-x x x$

Berger, L. M., \& Brooks-Gunn, J. (2005). Socioeconomic status, parenting knowledge and behaviors, and perceived maltreatment of young low-birth-weight children. The Social Service Review, 79, 237-268.

Berger, L. M., Paxson, C., \& Waldfogel, J. (2009). Mothers, men, and child protective services involvement. Child Maltreatment, 14, 263-276.

Bugental, D. B., Martorell, G. A., \& Barraza, V. (2003). The hormonal costs of subtle forms of infant maltreatment. Hormones and Behavior, 43, 237-244.

Chaffin, M., Silovsky, J. F., Funderburk, B., Valle, L. A., Brestan, E. V., Balachova, T., Jackson, S., Lensgraf, J., \& Bonner, B. L. (2004). Parent-child interaction therapy with physically abusive parents: Efficacy for reducing future abuse reports. Journal of Consulting and Clinical Psychology, 72, 500-510.

Chung, E., Mathew, L., Rothkopf, A. C., Elo, I. T., Coyne, C., \& Culhane, J. (2009). Parenting attitudes and infant spanking: The influence of childhood experiences. Pediatrics, 124, e278-e286.

Combs-Orme, T., \& Cain, D. S. (2008). Predictors of mothers' use of spanking with their infants. Child Abuse \& Neglect, 32, 649-657.

Crandall, M., Chiu, B., \& Sheehan, K. (2006). Injury in the first year of life: Risk factors and solutions for high-risk families. Journal of Surgical Research, 133, $7-10$.

Drake, B., Jolley, J. M., Lanier, P., Fluke, J., Barth, R. P., \& Jonson-Reid, M. (2011). Racial bias in child protection? A comparison of competing explanations using national data. Pediatrics, 127, 471-478.

Dubowitz, H., Kim, J., Black, M. M., Weisbart, C., Semiatin, J., \& Magder, L. S. (2011). Identifying children at high risk for a child maltreatment report. Child Abuse \& Neglect, 35, 96-104.

Durrant, J. E., \& Ensom, R. (2012). Physical punishment of children: Lessons from 20 years of research. Canadian Medical Association Journal, 184, 1373-1377.

Evans, W. D., Wallace, J. L., \& Snider, J. (2012). Pilot evaluation of the text4baby mobile health program. BMC Public Health, 12.

Gershoff, E. T. (2002). Corporal punishment by parents and associated child behaviors and experiences: A meta-analytic and theoretical review. Psychological Bulletin, 128, 539-579.

Gershoff, E. T. (2013). Spanking and child development: We know enough now to stop hitting our children. Child Development Perspectives, 7(3), 133-137.

Gershoff, E. T., Grogan-Kaylor, A., Lansford, J. E., Chang, L., Zelli, A., Deater-Deckard, K., \& Dodge, K. A. (2010). Parent discipline practices in an internationa sample: Associations with child behaviors and moderation by perceived normativeness. Child Development, 81, 487-502.

Gershoff, E. T., Lansford, J. E., Sexton, H. R., Davis-Kean, P. E., \& Sameroff, A. J. (2012). Longitudinal links between spanking and children's externalizing behaviors in a national sample of White, Black, Hispanic, and Asian American Families. Child Development, 83, 838-843.

Gigerenzer, G. (2011). What are natural frequencies? British Medical Journal, 343, d6386.

Gagne, M., Tourigny, M., Joly, J., \& Pouliot-Lapointe, J. (2007). Predictors of adult attitudes toward corporal punishment of children. Journal of Interpersonal Violence, 22, 1285-1304.

Grogan-Kaylor, A. (2004). The effect of corporal punishment on antisocial behavior in children Social Work Research, 28, 153-162.

Hemenway, D., Solnick, S. \& Carter, J. (1994). Child-rearing violence. Child Abuse E Neglect, 18, 1011-1020.

Hussey, J. M., Marshall, J. M., English, D. J., Knight, E. D., Lau, A. S., Dubowitz, H., \& Kotch, J. B. (2005). Defining maltreatment according to substantiation: Distinction without a difference? Child Abuse \& Neglect, 29, 479-492.

Jordan, E. T., Ray, E. M., Johnson, P., \& Evans, W. D. (2011). Text4Baby: Using text messaging to improve maternal and newborn health. Nursing for Women's Health, 15, 206-212.

Kessler, R. C., Andrews, G., Mroczek, D., Ustun, B., \& Wittchen, H. U. (1998). The World Health Organization composite international diagnostic interview short-form (CIDI-SF). International Journal of Methods in Psychiatric Research, 7, 171-185.

Kohl, P. L., Jonson-Reid, M., \& Drake, B. (2009). Time to leave substantiation behind: Findings From a national probability Study. Child Maltreatment, 14 $17-26$.

Lee, S. J., Altschul, I., \& Gershoff, E. T. (2013). Does warmth moderate longitudinal associations between maternal spanking and child aggression in early childhood? Developmental Psychology, 49(11), 2017-2028.

Lee, S. J., Taylor, C. A., Altschul, I., \& Rice, J. (2013). Parental spanking and subsequent risk for child aggression in father-involved families of young children. Children and Youth Services Review, 35, 1476-1485.

Long, J. S., \& Freese, J. (2005). Regression models for categorical outcomes using Stata (2nd ed.). College Station, TX: Stata Press.

MacKenzie, M. J., Nicklas, E., Brooks-Gunn, J., \& Waldfogel, J. (2011). Who spanks infants and toddlers? Evidence from the fragile families and child well-being study. Children and Youth Services Review, 33, 1364-1373.

Maguire-Jack, K., Gromoske, A. N., \& Berger, L. M. (2012). Spanking and child development during the first five years of life. Child Development, 83, 1960-1977.

McCormick, K. F. (1992). Attitudes of primary care physicians toward corporal punishment. Journal of the American Medical Association, 267, 3161-3165.

McDaniel, M., \& Slack, K. S. (2005). Major life events and the risk of a child maltreatment investigation. Children and Youth Services Review, 27, 171-195.

Nam, Y., Meezan, W., \& Danziger, S. K. (2006). Welfare recipients' involvement with child protective services after welfare reform. Child Abuse \& Neglect, 30, 1181-1199.

Patterson, G. R. (1982). Coercive family process. Eugene, OR: Castalia.

American Academy of Pediatrics. (2010). Connected kids: Safe, strong, secure. Retrieved from http://www.aap.org

Reich, S. M., Penner, E. K., Duncan, G. J., \& Auger, A. (2012). Using baby books to change new mothers' attitudes about corporal punishment. Child Abuse \& Neglect, 36, 108-117.

Reichman, N. E., Teitler, J. O., Garfinkel, I., \& McLanahan, S. S. (2001). Fragile families: Sample and design. Children and Youth Services Review, 32, 303-326.

Scholer, S. J., Hudnut-Beumler, J., \& Dietrich, M. S. (2010). A brief primary care intervention helps parents develop plans to discipline. Pediatrics, 125, e242-e249.

Scholer, S. J., Nix, R. L., \& Patterson, B. (2006). Gaps in pediatricians' advice to parents regarding early childhood aggression. Clinical Pediatrics, 45, 23-28.

Scholer, S. J., Reich, S. M., Boshers, R., \& Bickman, L. (2011). A brief program improves counseling of mothers with children who have persistent aggression. Journal of Interpersonal Violence, 27, 991-1004.

Slack, K. S., Berger, L. M., Dumont, K., Yang, M. Y., Kim, B., Ehrhard-Dietzel, S., \& Holl, J. L. (2011). Risk and protective factors for child neglect during early childhood: A cross-study comparison. Children and Youth Services Review, 33, 1354-1363.

Smith, T. W., Marsden, P. V., \& Hout, M. (2013). General social survey, 1972-2010 [Cumulative File]: Inter-university Consortium for Political and Social Research [distributor].

Straus, M. A. (2011). History and trends in research on spanking. In Paper presented at the Global Summit on Ending Corporal Punishment and Promoting Positive Discipline Dallas, TX

Straus, M. A., \& Stewart, J. H. (1999). Corporal punishment by American parents: National data on prevalence, chronicity, severity, and duration, in relation to child and family characteristics. Clinical Child and Family Psychology Review, 2, 55-70.

Taylor, C. A., Al-Hiyari, R., Lee, S. J., Priebe, A., \& Guerrero, L. W. (2014). Attitudes and ideologies linked with approval of corporal punishment in the U.S.: An online comment content analysis. Manuscript submitted for publication.

Taylor, C. A., Lee, S. J., Guterman, N. B., \& Rice, J. (2010). Use of spanking for 3-year-old children and associated intimate partner aggression or violence. Pediatrics, $126,415-424$

Taylor, C. A., Manganello, J. A., Lee, S. J., \& Rice, J. (2010). Mothers' spanking of 3-year-old children and subsequent risk of children's aggressive behavior Pediatrics, 125, e1057-e1065.

Trickett, P. K., \& Kuczynski, L. (1986). Children's misbehaviors and parental discipline strategies in abusive and nonabusive families. Developmental Psychology, 22, 115-123.

U.S. Department of Health and Human Services, Administration for Children and Families, \& Administration on Children, Youth and Families, Children's Bureau. (2012). Child Maltreatment 2012. Retrieved from Available from http://www.acf.hhs.gov/programs/cb/research-datatechnology/statistics-research/child-maltreatment 
Viera, A. J. (2008). Odds ratios and risk ratios: What's the difference and why does it matter? Southern Medical Journal, $101,730-734$.

Whittaker, R., Matoff-Stepp, S., Meehan, J., Kendrick, J., Jordan, E., Stange, P., Cash, A., Meyer, P., Baitty, J., Johnson, P., Ratzan, S., \& Rhee, K. (2012). Text4baby: Development and implementation of a national text messaging health information service. American Journal of Public Health, $102,2207-2213$.

Wu, S. S., Ma, C. X., Carter, R. L., Ariet, M., Feaver, E. A., Resnick, M. B., \& Roth, J. (2004). Risk factors for infant maltreatment: A population-based study. Child Abuse \&' Neglect, 28, 1253-1264.

Zolotor, A. J., Robinson, T. W., Runyan, D. K., Barr, R. G., \& Murphy, R. A. (2011). The emergence of spanking among a representative sample of children under 2 years of age in North Carolina. Frontiers in Psychiatry: Child and Neurodevelopmental Psychiatry, 2, 1-8.

Zolotor, A. J., Theodore, A. D., Chang, J. J., Berkoff, M. C., \& Runyan, D. K. (2008). Speak softly - and forget the stick: Corporal punishment and child physical abuse. American Journal of Preventive Medicine, 35, 364-369. 